(C) 2015. This manuscript version is made available under the CC-BY-NC-ND 4.0 license http:// creativecommons.org/licenses/by-nc-nd/4.0/ (Publisher Journal website as of 21/11/2018) https:// www.elsevier.com/about/policies/sharing/how-to-attach-a-user-license

\title{
2 A new framework for selecting environmental surrogates
}

3

4 David Lindenmayer $^{\mathrm{a}^{*}}$, Jennifer Pierson ${ }^{\mathrm{a}}$, Philip Barton ${ }^{\mathrm{a}}$, Maria Beger ${ }^{\mathrm{b}}$, Cristina Branquinho $^{\mathrm{c}}$, 5 Aram Calhoun $^{\mathrm{d}}$, Tim Caro ${ }^{\mathrm{e}}$, Hamish Greig ${ }^{\mathrm{f}}$, John Gross ${ }^{\mathrm{g}}$, Jani Heino ${ }^{\mathrm{h}}$, Malcolm Hunter ${ }^{\mathrm{d}}$,

6 Peter Lane $^{\mathrm{a}}$, Catherine Longo ${ }^{\mathrm{i}}$, Kathy Martin', William H. McDowell ${ }^{\mathrm{k}}$, Camille Mellin',

7 Hanna Salo ${ }^{\mathrm{m}}$, Ayesha Tulloch ${ }^{\mathrm{n}}$, and Martin Westgate

$9 \quad{ }^{a}$ Fenner School of Environment and Society, The Australian National University, 141

10 Linnaeus Way, Acton, Australian Capital Territory 2601, Australia

$11{ }^{\mathrm{b}}$ Centre for Biodiversity and Conservation Science, The University of Queensland, St Lucia,

12 Queensland 4072, Australia

$13{ }^{\mathrm{c}}$ Centre for Ecology, Evolution and Environmental Changes, Faculdade de Ciências,

14 Universidade de Lisboa, Campo Grande, Bloco C2, 1749-016, Lisboa, Portugal

$15{ }^{\mathrm{d}}$ Department of Wildlife, Fisheries, and Conservation Biology, University of Maine, Orono

16 Maine, USA

17 e Department of Wildlife, Fish and Conservation Biology, University of California, Davis,

18 California 95616, USA

19 f School of Biology and Ecology, University of Maine, Orono Maine, USA

$20{ }^{\mathrm{g}}$ Climate Change Response Program, United States National Park Service, 1201 Oakridge

21 Drive, Fort Collins, Colorado 80525, USA

$22{ }^{\mathrm{h}}$ Finnish Environment Institute, Natural Environment Centre, Biodiversity, P.O. Box 413, FI-

2390014 Oulu, Finland

$24{ }^{i}$ National Center for Ecological Analysis and Synthesis, University of California, Santa 25 Barbara, California, USA 
${ }^{\mathrm{j}}$ Department of Forest and Conservation Sciences, University of British Columbia,

Vancouver Canada, V6T 1 Z4

${ }^{\mathrm{k}}$ Department of Natural Resources and the Environment, University of New Hampshire,

29 Durham, New Hampshire 03824, USA

$30{ }^{1}$ Australian Institute of Marine Science, PMB No. 3, Townsville MC, Townsville,

31 Queensland 4810, Australia

$32{ }^{\mathrm{m}}$ Department of Geography and Geology, University of Turku, Turku Finland

*Corresponding author: david.lindenmayer@anu.edu.au, Fenner School of Environment and

Society, The Australian National University, 141 Linnaeus Way, Acton, Australian Capital

Territory 2601, Australia

\section{Abstract}

Surrogate concepts are used in all sub-disciplines of environmental science. However, controversy remains regarding the extent to which surrogates are useful for resolving environmental problems. Here, we argue that conflicts about the utility of surrogates (and the related concepts of indicators and proxies) often reflect context-specific differences in tradeoffs between measurement accuracy and practical constraints. By examining different approaches for selecting and applying surrogates, we identify five trade-offs that correspond to key points of contention in the application of surrogates. We then present an 8-step Adaptive Surrogacy Framework that incorporates cross-disciplinary perspectives from a wide spectrum of the environmental sciences, aiming to unify surrogate concepts across disciplines and applications. Our synthesis of the science of surrogates is intended as a first step towards fully leveraging knowledge accumulated across disciplines, thus consolidating lessons 
learned so that they may be accessible to all those operating in different fields, yet facing similar hurdles.

Keywords: Indicators, proxies, environmental management, Adaptive Surrogacy

54 Framework, decision-making

55

\section{Introduction}

One of the most active research fields in applied ecology, conservation biology, and environmental and resource management focuses on surrogates, including indicator species and other related kinds of proxies (Niemi et al., 1997; McGeoch, 1998; Rodrigues and Brooks, 2007; Wiens et al., 2008; Caro, 2010). In an environmental context, a 'surrogate' is a component of the system of concern that one can more easily measure or manage than others, and that is used as an indicator of the attribute/trait/characteristic/quality of that system (Mellin et al., 2011). A wide range of concepts can be included under the broad topic of environmental surrogates including flagship species, focal species, indicator species, sentinel species, biomonitoring species, biomarker species, avatar species (sensu Larson and Olden, 2012) umbrella species, and many others (see Caro 2010 for a review). The use of surrogates is important and often necessary because resource constraints in monitoring and management require cost-effective yet useful ways to assess ecosystem responses and key ecological processes.

Figure 1. Many different kinds of surrogates are used in the environmental sciences. (a) Lichens as an ecological surrogate of atmospheric quality. (b) Fire regimes as surrogate for species extent and occurrence in fire-prone ecosystems. (c) Bumphead parrotfish (Bolbometopon muricatum) as a flagship species, signifying coral reef health/ sustainable 

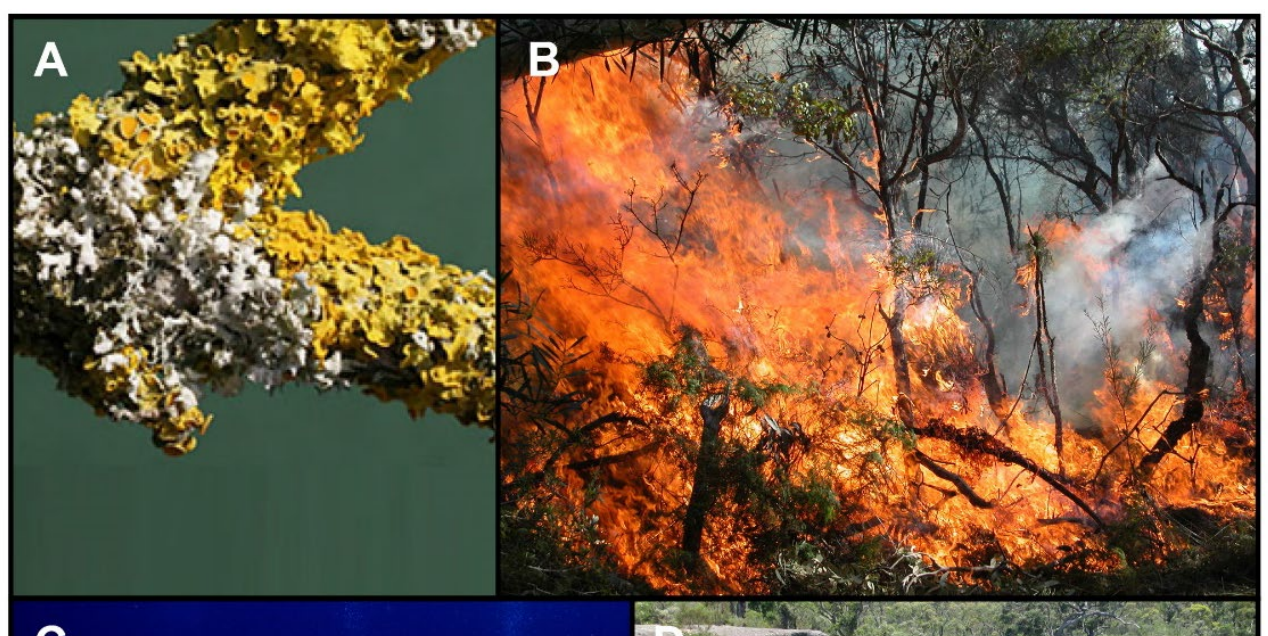

\section{C}

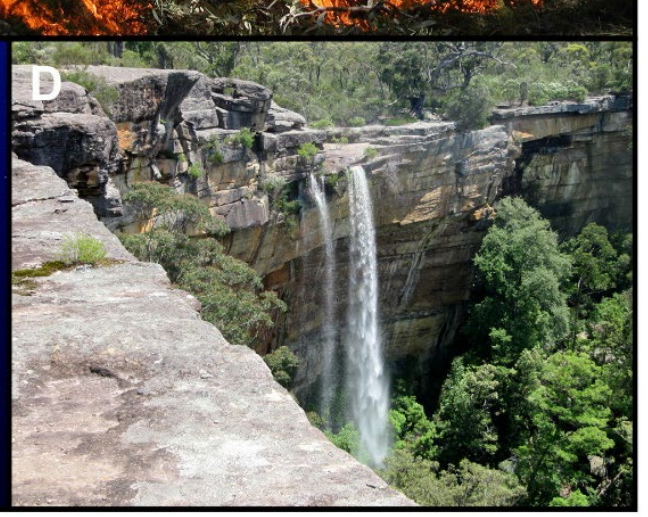

Because surrogates are employed in many disciplines, most of the scientific research

on the conceptual development and testing of surrogates occurs independently rather than in

concert. This leads to the compartmentalization of knowledge, resulting in large differences

in understanding between fields of research (Box 1), a process exemplified by some recent reviews targeted at a small subset of the wider 'surrogate community' (e.g. Rodrigues and

Brooks, 2007; Collen and Nicholson, 2014). Consequently, there has often been limited

knowledge transfer across disciplines with innovations in some fields ignored or unknown in others (Barton et al., 2015). For example, surrogacy within ecology and conservation has developed in isolation from the more systematic approach to validating and evaluating surrogates in clinical medicine, especially clinical pharmacology and therapeutics (Barton et 
al., 2015). This includes the robust conceptual frameworks for selecting surrogates with desirable properties in terms of functional behavior, rigorous statistical protocols, end-user needs, and formal evaluation of performance (such as sensitivity analyses and goodness of fit testing) (Buyse and Molenberghs, 1998). There are a range of reasons for differential development of surrogates in different disciplines. For example, the rapid and extensive development of medical surrogates relative to the environmental sciences reflects the prolonged period of use (spanning centuries) in the former and the corresponding very large quantity of resources dedicated to surrogate identification, testing and application. Despite the widespread use of surrogates in different environmental disciplines, there has been considerable criticism of their application (Andelman and Fagan, 2000; Lindenmayer et al., 2000; Seddon and Leech, 2008; Caro, 2010). Indeed, there have been some mistakes or perverse outcomes with significant environmental, policy, legal and other consequences resulting from a poor approach to surrogate use (e.g. Branch et al., 2010; Euliss and Mushet, 2011; Saraux et al., 2011). From the broad cross-disciplinary perspective taken in this paper, we argue that some of the discussion about the pros and cons of surrogates reflects disagreement over the best way to assess and manage environmental problems in the context of key trade-offs, practical constraints, and uncertainty.

It is well established that the best surrogates are those that are cheap and feasible to measure or manage, are representative of the species or processes of interest, yet still respond

108 in timely and predictable ways to changes in the environment (Niemeijer and de Groot,

109 2008). But it is often the case that surrogates do not have all of these characteristics

110 simultaneously. In this case, which surrogate should be preferred? A useful way to support

111 the decision-making process for selecting surrogates is to categorize, understand, and identify

112 a parsimonious number of priority trade-offs to be evaluated. Key criteria in this process

113 relate to the quality of a surrogate (such as the uncertainty associated with the surrogate- 
114 target relationship), and the feasibility of using it (e.g. measurement cost). However, to the

115 best of our collective knowledge, these (and other) trade-offs are rarely explicitly considered

116 in the selection and application of surrogates (Wiens et al., 2008).

117 Below, we develop a new conceptual Adaptive Surrogacy Framework to explicitly

118 address five, often strongly inter-related trade-offs: (1) whether it is better to employ

119 surrogates or address (e.g. measure) an entity directly, (2) the accuracy versus generality of a surrogate, (3) the temporal stability of a surrogate versus its ability to detect change over time, (4) simple communication value versus communication complexity associated with caveats and details of methodology, and, (5) cost-effectiveness versus certainty. Our new framework is characterised by inter-linked and iterative identification, application, and evaluation steps for continuous testing and improvement. We argue that our Adaptive Surrogacy Framework is suitable for use in all fields where environmental surrogates are employed. It builds on a synthesis of similarities and differences in how different disciplines apply surrogates in atmospheric, freshwater, terrestrial, and marine systems. To place our new framework into an appropriate context, we first highlight what we have identified as five key trade-offs that need to be considered in most uses of surrogates.

BOX 1. Differences in the use and application of ecological surrogates across disciplines

Surrogates appear to be better developed when they are applied to measure atmospheric or water pollution (Ares et al., 2012; Augusto et al., 2012; Barros et al., 2015), than, for example, to assess complex emergent properties such as ecosystem integrity. For instance, the use of ecological surrogates in monitoring atmospheric pollution, marine coliforms, aquatic heavy metal concentrations, and shellfish toxins is underpinned by an agreed set of methods and protocols, fine-tuned benchmarks, and systematic ways to account for uncertainty and analyse and interpret data (Augusto et al., 2013). These innovations are 
lacking in some other areas such as, for example, monitoring programs that aim to document temporal changes in the conservation status of terrestrial biodiversity (Lindenmayer and Likens, 2010).

To some extent, differences in surrogate development among fields reflect the direct effects of environmental conditions on human health (Augusto et al., 2012; Ribeiro et al., 2014). The amount of knowledge (and hence scientific and management progress) about ecological surrogates is strongly biased toward issues that directly affect humans because inappropriate decisions can have direct, societally-relevant consequences, such as economic losses and major objective of this paper.

threats to human health and safety. For example, innovations in surrogate thresholds, reference points, and robustness for food-web integrity have been extensively applied in marine systems (Cury and Christensen, 2005; Gray et al., 2014; Libralato et al., 2014), in contrast with similar metrics applied to terrestrial or freshwater systems that often lack these complexities. It is probably not coincidental that innovative studies are motivated by the management of a human activity (e.g., fisheries) that has strong social and economic implications.

There are four important common themes among disciplines in the development of ecological surrogates. These are the need to: (i) identify well-developed goals for the use of ecological surrogates (McGeoch, 1998; Collen and Nicholson, 2014); (ii) develop a robust conceptual model of the system in question to then guide the identification of appropriate surrogates (Niemeijer and de Groot, 2008); (iii) rigorously test ecological surrogates (Bockstaller and Girardin, 2003); and (iv) overcome widespread problems of translating the body of science on ecological surrogates into a form that effectively informs managers and decision-makers, or even the wider public (Halpern et al., 2012; Westgate et al., 2014), a 


\section{Five key trade-offs common to environmental disciplines using surrogates}

2.1. Surrogacy versus directly addressing a target. This issue is exemplified by ecological

monitoring for which a fundamental issue is whether it is possible or desirable to measure a

167 process directly, or whether a surrogate approach should be preferred (Lindenmayer and

168 Likens, 2011). Many factors will influence this decision, but in general, the need for a

169 surrogate can be thought of as proportional to the complexity or difficulty in measurement of the variable of interest. Simple targets are often readily identified and can be measured and managed directly (e.g., the concentration of a heavy metal in the atmosphere), and a decision must be made about whether it might be best to measure the entity directly, or if a surrogate measure might be cheaper or quicker (see Trade-off \#5 below). In contrast, some properties of ecological systems are so complex that it is impossible to measure them directly or in their entirety (e.g. the 'health' or 'integrity' of an ecosystem, due to the sheer magnitude of its component parts and difficulties in defining it quantitatively), and this necessitates surrogate use. A further consideration when choosing between direct measurement and surrogate methods is whether there are several indirect linkages between the surrogate and its target that may reduce the precision or accuracy with which the process of interest can be evaluated (Figure 2). It is important to consider the external factors that might interact with the surrogate-target relationship and thereby obscure accurate surrogacy (see Trade-off \#2 below). These include: (i) the complexity of the target, (ii) the boundaries of applicability of the surrogate, (iii) the distance from the target in the causal network, and (iv) the number of possible pathways linking a surrogate to a target through other covariates. measured by satellites is routinely used as a surrogate for marine primary productivity, rather 
biases and demanding processing techniques, the spatial coverage that can be achieved through satellite imagery is unmatched. Similarly, satellite imagery of forest 'burn scars' can

191 be successfully used as a surrogate measure of fire dynamics and health of forests that are too

192 remote and too vast to be assessed directly (Lentile et al., 2006).

Finally, there may be cases where the best strategy might be to alternate between a

194 direct measurement and a surrogate approach depending on, for example, the frequency of monitoring, the kinds of stressors in a given ecosystem, the difficulty of detecting change over time in particular kinds of environmental parameters, and a range of other factors.

Figure 2. A conceptual depiction of how the relationship between the surrogate $(\mathrm{S})$ and the target $(\mathrm{T})$ can become more complicated the further removed a surrogate is from the target, i.e., as the functional connection between surrogate and target becomes less direct. Compare the first surrogate $\left(\mathrm{S}_{1}\right)$ that is directly related to the target, with the second surrogate $\left(\mathrm{S}_{2}\right)$ that is one step removed from the target. The third surrogate $\left(\mathrm{S}_{3}\right)$ is further removed again via $\mathrm{S}_{1}$ and $\mathrm{S}_{2}$, but is also related to the target directly and via an unmeasured variable (U).

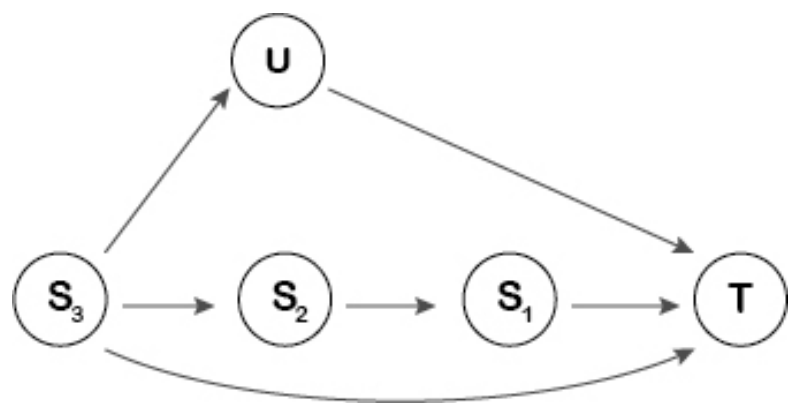

2.2 Accuracy versus generality. In all disciplines, the applicability of surrogates involves a trade-off between the accuracy of the surrogate's representation of the target and the transferability of that surrogate. Some surrogates are developed to be applicable to very specific locations or conditions, whereas others can be applied across a broad range of areas.

209 For example, the Ocean Health Index (Halpern et al., 2012) is a compound metric developed 210 to be broadly applicable across the world. By contrast, a particular bird species might be 
211 identified as a good indicator of restoration success only within a particular landscape. The

212 stronger the mechanistic link between surrogate and target, the more appropriate the

213 surrogate is likely to be (Figure 2). For example, managing herbivore abundance as a

214 surrogate for managing grassland productivity is likely to be a better surrogate than managing

215 predator abundance, which is one trophic level removed from the direct target of interest.

216 This is partially because the greater the number of causal pathways that link a surrogate to its

217 target (see Figure 2), the greater the uncertainty about the relationship. Put differently, an

218 accurate understanding of the relationship between a surrogate and its target can be

219 complicated (or even obscured) by hidden effects and interactions among variables. Indeed,

220 the more covariates influencing the accuracy of a surrogacy relationship in a given area, the

221 less likely that the surrogate will be readily transferable to a more distant area or a different ecosystem where those covariates are likely to have different values (e.g. Travers et al., 2006).

2.3. Temporal stability versus change over time. A conundrum associated with ecological surrogates is the tension between applying a surrogate that responds quickly and consistently to a change of interest in a given system (responsiveness), in a way that is detectable (sensitivity), yet at the same time is robust to changes in the ecosystem that are not of direct interest (specificity) (Rice, 2003; Barton et al., 2015). Uncertainty in future conditions can have a strong influence on the surrogate-target relationship. Climate change and stochastic

230 events, such as fire, floods, drought, storms, or outbreaks of insects and/or pest population

231 can result in unanticipated shifts in this relationship. The spatial stability of a surrogate to

232 detect changes at particular scales is also an important consideration. That is, an

233 understanding of the location boundaries within which a surrogate will be effective but

234 beyond which it will not. 
To demonstrate the trade-offs between these surrogate properties, consider the process of identifying an ecological surrogate to assess the effectiveness of invasive red fox (Vulpes vulpes) population control in Australia for biodiversity protection. Decision-makers need a surrogate that, when monitored, provides feedback on whether the level of management being undertaken has been effective at reducing fox populations and increasing native prey populations. Native species will differ in the rate of their response to fox control, as well as in the degree to which those responses can be detected by monitoring, each of which influences their suitability as a surrogate (Tulloch et al., 2013). However, as time passes since management began, there is an associated increase in the possibility that fox removal will

244 lead to unanticipated changes in the system, such as mesopredator release of invasive (feral) cats (Felis catus) (Doherty et al., 2015). This might change the relationship between abundance of the surrogate and fox management, depending on how sensitive a given species is to fox predation versus cat predation. Therefore, surrogates need to be found that reflect temporal changes in the system due to fox removal, while remaining robust to uncertain

249 future conditions such as increases in cat populations. A solid understanding of the

250 underlying temporal patterns of variability in the target ecosystem, as well as the potential influence of stochastic processes on surrogate relationships, is therefore critical to provide context for understanding variability in a surrogate-target relationship. In some cases the ability to track change will not be able to be met by any one surrogate (van Straalen, 1998),

254 thereby highlighting the potential value of having multiple surrogates (Victor and Kennel, 255 2014).

2.4. Simplicity versus complexity in communication value. A key part of the successful development of ecological surrogates is to engage all stakeholders at the outset and that is easier with a surrogate that resonates with a broad and diverse audience. This is neatly demonstrated in vernal pool or temporary pond ecosystems in the north-eastern USA, where 
the charismatic spotted salamander (Ambystoma maculatum) is used as a flagship species as it is an attractive symbol of spring (Calhoun et al., 2014). Similarly, the composite Ocean Health Index (Halpern et al., 2012) has significant communication value because it is a simple number that incorporates a range of ecological, social, and economic attributes in a

264 single standardised framework. However, the inherent nature of surrogates (being simplified 265 attributes that require several assumptions), means that there are often caveats and technical nuances that are likely to be lost in attempts to communicate with a non-scientific audience

267 (e.g. Evans et al., 2015). In these cases, efforts should be made to communicate the key scientific limitations of a given surrogate to the stakeholders involved in the surrogate development process, as well as to broader audiences (Lindenmayer and Fischer, 2003). For instance, the spotted salamander is attractive (Figure 3), but it is primarily an indicator of one aspect of vernal pool ecology - the hydroperiod. It is not a comprehensive umbrella species (sensu Caro, 2010) for vernal pools as the other animals in these ecosystems have different life history needs, with some depending on different hydroperiods (Calhoun and deMaynadier, 2008). Communicating these limitations to the public can be a valuable objective, although it is important not to completely void the species' publicly-perceived value as a surrogate in the process.

Figure 3. Spotted Salamander (Ambystoma maculatum) from north-eastern USA. This species is used as a flagship species as it is attractive to the public. However, it is a surrogate primarily for one aspect of vernal pool ecology - the hydroperiod - and so is not an umbrella species (sensu Caro, 2010) as other species associated with these ecosystems have different requirements (Calhoun and deMaynadier, 2008). (Image K. Hoffman) 


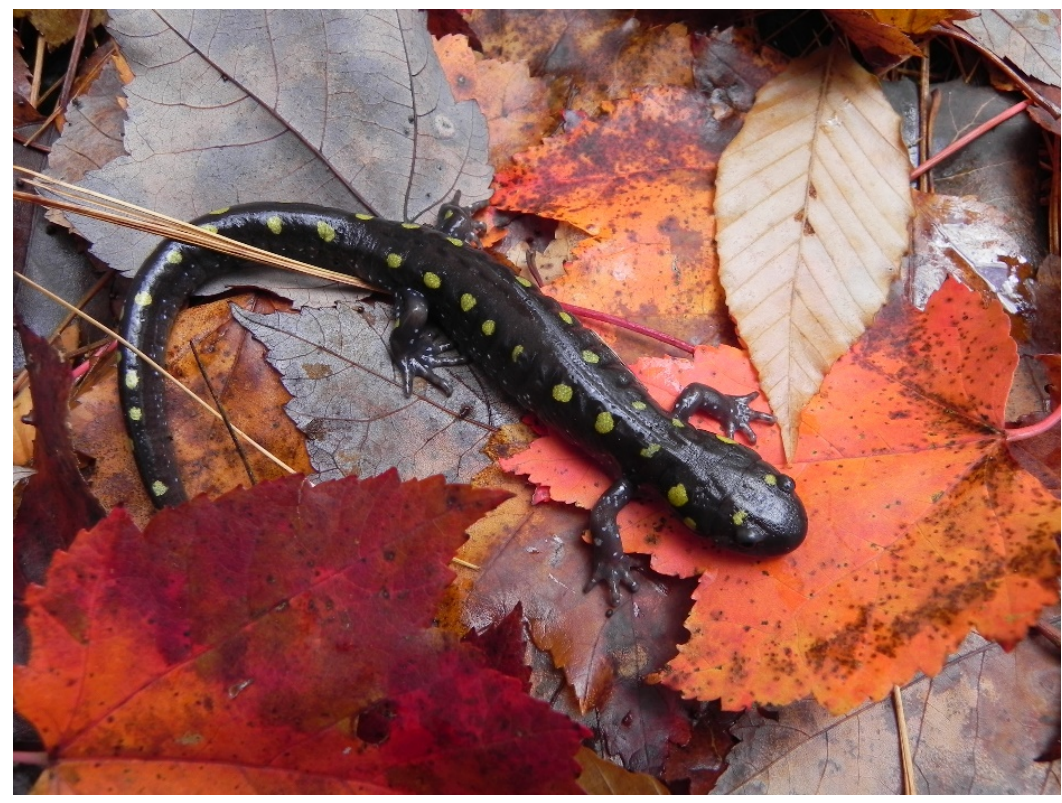

2.5. Cost-effectiveness versus certainty. The cost-effectiveness of ecological surrogates is often not quantified (although see Mandelik et al., 2010; Tulloch et al., 2011; Peck et al., 2014). Yet cost (either financial or time and effort) is one of the key reasons for selecting a cheaper surrogate rather than a direct measure in the first place (see Trade-off \#1). Those studies that have compared the costs of potential surrogates are mostly completed post hoc (Kessler et al., 2010; Peck et al., 2014). In some instances existing knowledge (from experts or literature review) can be sufficient to make effective surrogate selection decisions, thus avoiding expensive large-scale experimental monitoring comparing different survey methods and multiple taxa that might be the best surrogates (Tulloch et al., 2011). Ideally, any comprehensive analysis of a surrogate approach should include the cost of identifying and evaluating the efficacy of a proposed surrogate (see Figure 4), which relates to the uncertainty about the target resulting from using the surrogate. Typically, the cost comparison is confined to comparing the application of different surrogates (Kessler et al., 2010), or the application of surrogates versus a direct approach (Lindenmayer and Likens, 2011). Even when cost-effectiveness has been considered in surrogate selection, the level of certainty in the information that surrogate provides is rarely evaluated (but see Gardner, 2010; Tulloch et al., 2011). The cheapest surrogate probably holds additional risks of missing 
301 critically important information that might have been identified with a more expensive surrogate. Cost-effectiveness analyses can explore these risks by calculating the hidden costs of selecting the wrong surrogates, particularly if there is a chance of incorrect or suboptimal

304 surrogate choice leading to management mistakes (e.g. Saraux et al., 2011). In cases of

305 significant uncertainty in (and risks associated with) the most cost-effective surrogate, formal

306 risk assessment will assist in developing and applying ecological surrogates that are robust to uncertainty.

As demonstrated in Trade-off \#3, multiple surrogates can be used in combination to

309 reduce uncertainty. Assuming that uncertainty stems from system covariates that change or

310 conflate the surrogate response, a suite of surrogates, chosen so they are as orthogonal as

311 possible, can reduce the risk of misinterpretation. In this case, a cost-benefit analysis will

312 need to consider costs of multiple combinations of indicators and their combined

313 performance. Although the use of multiple surrogates is often recommended (e.g. Rice and

314 Rochet, 2005; Niemeijer and de Groot, 2008), and recommendations for selection criteria

315 exist (Nardo et al., 2008), in practice, the selection of multiple surrogates is often

316 opportunistic rather than optimized for the most parsimonious and cost-effective set of

317 complementary measures. Nonetheless, there are some examples of risk analysis to prioritize

318 key entities to monitor (McManus et al., 2014)

320 Figure 4. The adaptive surrogacy framework showing links and feedback loops between the

321 seven components, and sub-components, that might be considered in the development,

322 application, and learning about surrogates. 


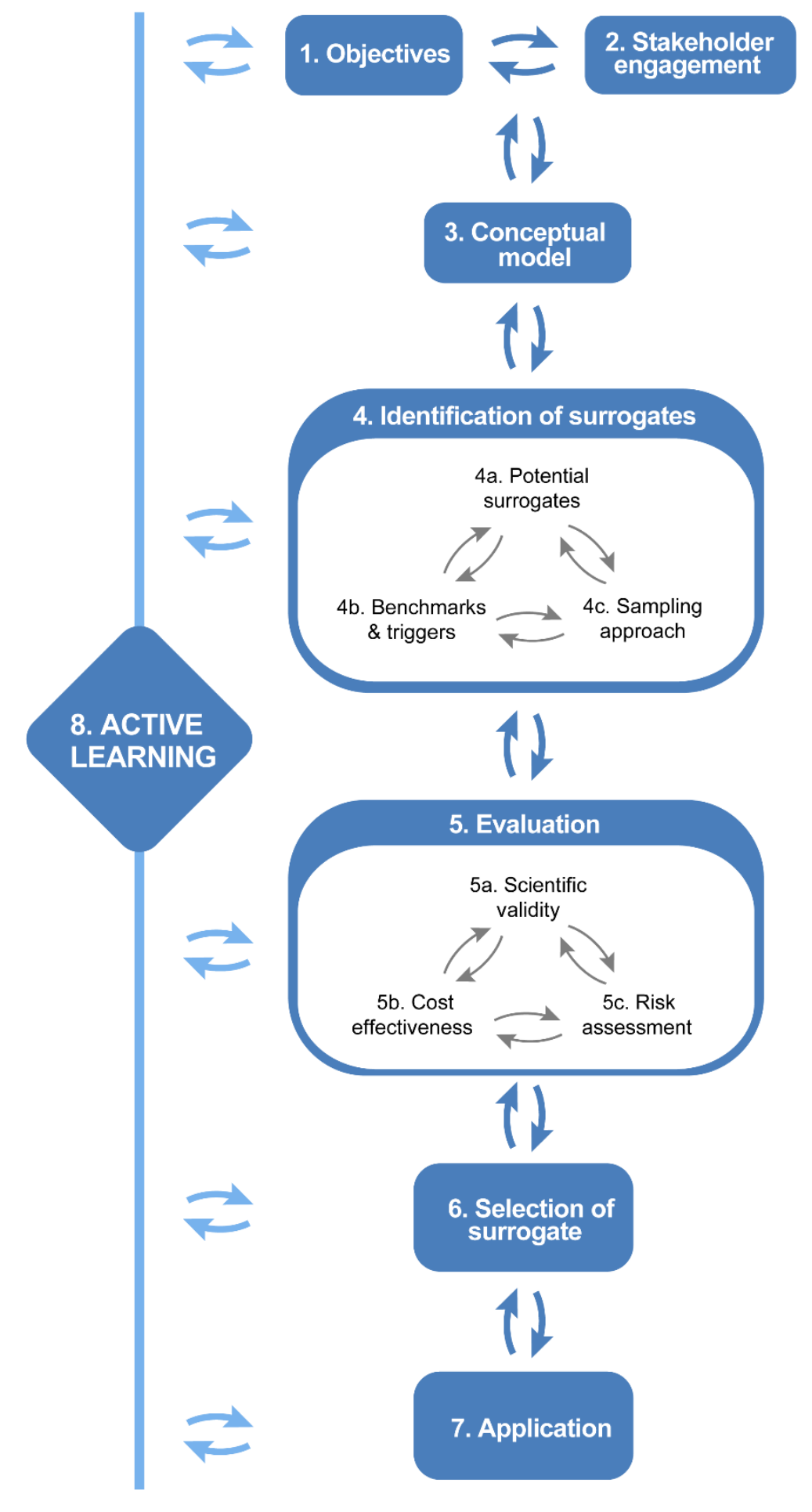

We propose a new Adaptive Surrogacy Framework (see Figure 4) to specifically

327 address trade-offs and uncertainties outlined in the preceding section and better guide the use

328 of robust surrogate measures. The scientific underpinnings of the Adaptive Surrogacy 
329 Framework include hypothesis testing and risk assessment, where proposed surrogates are

330 treated as working hypotheses to be subjected to rigorous testing. This provides a formal

331 framework to continuously improve the application of surrogates. We acknowledge that

332 sometimes monitoring of surrogates may not be hypothesis driven but in these cases it will

333 nevertheless be important that there is at least some understanding of the baseline

334 behaviorbehaviorbehaviour of the measure in question where unexpected values can readily

335 be identified and trigger appropriate action (such as a targeted management intervention

336 and/or additional research) (Wintle et al., 2010; Friberg et al., 2011)

\section{3.1. Identify objectives}

338 It is not possible to determine the effectiveness of an ecological surrogate without an

339 objective against which to judge its efficacy (Wiens et al., 2008). Most often, this objective is

340 linked to the aspect of the system that we want to address but which cannot be approached

341 directly; however, it also includes defining what constitutes surrogacy success. The clearer

342 the endpoint, the easier it will be to select the optimal surrogate(s), and defend the process

343 scientifically. SMART (specific, measurable, attainable, relevant, time-bound) principles are

344 useful in these cases (Samhouri et al., 2012). It is easy to confuse program goals, monitoring

345 goals, management objectives, and sampling objectives (Fancy and Bennetts, 2011). The use

346 of surrogates further complicates identifying and articulating clear objectives because

347 surrogates only represent the attribute of interest, or even may represent only a subset of the

348 attribute of interest. The need for clear objectives is stressed in virtually every treatise on

349 monitoring and management (Gardner, 2010; Lindenmayer and Likens, 2010) but the

350 literature on ecological surrogates is replete with innumerable examples where the objectives

351 of surrogate application has not been articulated (Caro, 2010). 


\subsection{Identify and engage stakeholders}

Stakeholders should be engaged in all phases of surrogacy development to capitalize on the collective experience, expertise, and wisdom of people with diverse perspectives. This approach ensures ownership of both the process and decision points, ultimately leading to more robust outcomes, and is crucial for being able to understand and deal with the trade-off between communication value and scientific defensibility of a surrogate (see Trade-off \#4 above). For example, (Calhoun et al., 2014) describes an approach for engaging stakeholders in developing a surrogate for temporary ponds (i.e., egg mass number thresholds for various breeding amphibians). The stakeholders were able to find common ground that did not conflict with the mandates of their major constituencies. From this foundation, more complex management strategies could be developed. Successful examples of stakeholder engagement in different steps of surrogate use, from goal-setting, to iterative steps leading to more refined indicators, targets, and reference points, can also be found in some marine adaptive management efforts, such as the case of Raja Ampat in Indonesia, or Puget Sound in the USA (Tallis et al., 2010). The need for broad stakeholder involvement underscores the importance of scientists engaging with the public, policy makers, and politicians to communicate widely the need for robust ecological surrogates (see Trade-off \#4 above). However, we also recognize that in some cases, stakeholders may be concerned about the status of some key aspect of the environment (e.g. the level of air pollution), but not interested in the details about how air quality is evaluated and hence the kind of surrogates that are used.

\subsection{Develop a conceptual model of the target system}

A key part of identifying an effective ecological surrogate is being able to articulate links between a surrogate and its target. This demands the development of a good conceptual model of the system at hand, starting with sufficient scientific knowledge about some of the key ecological processes and the potential interactions among processes and components, 
377

378

379

380

381

382

383

384

385

386

387

388

389

390

391

392

393

394

395

396

397

398

399

400

401

especially species. The use of a conceptual model can uncover the causal relationships between an ecological surrogate and the entity for which it is considered to be a proxy. That is, an ecological surrogate is more likely to be effective when there is a clear mechanistic relationship with the target (Figure 2). For example, Breckheimer et al. (2014) quantitatively evaluated the umbrella species concept in the context of landscape connectivity, which required a conceptual understanding of the dispersal capabilities of a surrogate (i.e. the umbrella species) and targets. Of course, while establishing causal relationships is the "gold standard" in the application of ecological surrogates, it can be extremely difficult to do (Samhouri et al., 2012). Indeed, a lot of money is invested in establishing causal relationships between surrogates and target endpoints in medicine (Buyse et al., 2010), environmental pollution (Millington and Walker, 1983), and in marine communities undergoing fishing pressure (Libralato et al., 2014) - and it is even harder to achieve in other ecological applications (McGill and Nekola, 2010). Nevertheless, conceptualising a study system in terms of a set of causal pathways between associated and interacting variables will greatly facilitate an understanding of $\boldsymbol{w h} \boldsymbol{y}$ a variable might be an effective surrogate. Once the $\boldsymbol{w h} \boldsymbol{y}$ is established, there is a far greater chance of the correct science being done to determine if the variable is effective. Building a conceptual model of the system is therefore a first step to addressing the important trade-off between accuracy and generality (see Trade-off \#2 above) (Barton et al., 2015), as well as forecasting how and when uncertainty in surrogate relationships might affect predicted outcomes (see Trade-offs \#3 and \#5).

\subsection{Identification of potential surrogates}

The identification of potential surrogates in our Adaptive Surrogacy Framework contains three inter-related sub-components set out below as steps $3 \mathrm{~A}, 3 \mathrm{~B}$, and $3 \mathrm{C}$, with iterative movement among them. For example, the selection of potential surrogates needs to be guided by a well-designed sampling strategy as well as appropriately established 
402 benchmarks or trigger points for management interventions (Figure 4). Therefore, designing a

403 potential sampling strategy for gathering surrogate data might have to come before the

404 selection of the surrogates - i.e. first determine potential sampling strategies for a few

405 surrogate candidates, second determine the benefits and costs of each of those strategies, and

406 lastly, select the appropriate surrogates based on benefit/cost trade-offs (see Trade-off \#5

407 above). Hence, difficulties in either sampling the surrogate or setting trigger points would

408 demand a different potential surrogate be identified. Below we discuss each of the sub-

409 components separately, but recognize the inter-relationships between them.

410 Sub-component 3.4A. Select potential ecological surrogates. The decision about which

411 surrogate(s) to select is often based on a combination of factors that include both scientific

412 validity and practical considerations such as budget limitations and legislative requirements

413 (as well as the outcomes of consideration of sub-components $4 \mathrm{~B}$ and $4 \mathrm{C}$ - see below). For

414 example, if threatened species are required by law to be monitored, then using a threatened

415 species as a surrogate may have an advantage over a non-threatened species. However,

416 threatened species may be difficult to detect, and may not necessarily represent the aspect of

417 interest to the same extent as a non-threatened, easily detected alternative. The trade-off

418 between detection, monitoring cost, and management cost may mean that the best decision is

419 to not monitor at all, but just expend resources in management (McDonald-Madden et al.,

420 2010). In some cases, there will be a need for multiple ecological surrogates for assessing the

421 same goal, particularly for complex ecosystems or problems (Victor and Kennel, 2014). For

422 example, a recent meta-analysis used two complementary genetic indicators to assess loss of

423 genetic diversity in overharvested populations of marine fishes (Pinsky and Palumbi, 2014).

424 This can limit the risk of selecting a poorly performing surrogate, and in turn, reduces the

425 chance of errors in interpretation or management. The use of multiple surrogates also can 
426 facilitate quantitative comparisons between the performances of different surrogates against 427 the same goal (Victor and Kennel, 2014), for example when examining cost-effectiveness. Sub-component 3.4B. Establish reference points and benchmarks. It can be important to establish clear reference points or benchmarks to assist interpretation of the performance of an ecological surrogate. This step is reliant on a good scientific understanding of the study system. What is the natural variation in a system compared to directional variation? For example, (Hansen et al., 2012) outline clear criteria for identifying adaptive genetic responses to change. Control or reference states are also valuable for accurate use of surrogates in ecosystem restoration (Barton and Moir, 2015) and pollution monitoring (Salo, 2015). Best practice application of ecological surrogates to management problems should include trigger points for management response (Pinho et al., 2012). These trigger points should occur well before ecological thresholds for an abrupt change in, for example, populations of species (Lindenmayer et al., 2013), species richness, or key ecological processes. In many ecological systems, identifying these thresholds remains a challenge (Kelly et al., 2015).

440 Sub-component 3.4C. Design a sampling approach to measure candidate surrogates. The sampling strategy to gather data about a surrogate should be based on the combination of management objectives (i.e., target of interest) and ecological attributes of the potential surrogates. For example, designing a study to assess air quality in Europe based on lichen

444 diversity may need to be stratified by areas associated with management and other objectives 445 (i.e., land-use type), while empirical data collection methods need to remain consistent and 446 also account for biogeographic variation in lichen assemblages. This could be accomplished 447 by examining functional responses to pollution, such as a shift from oligotrophic to 448 nitrophytic communities (Sutton et al., 2009). 
Evaluation is a critical part in the development of surrogates (Wiens et al., 2008) and has three distinct sub-components: (a) scientific validity; (b) cost-effectiveness; and (c) risk assessment. By identifying and evaluating uncertainty in, and cost-effectiveness of, alternative surrogates prior to acting, the trade-offs between these can be identified and dealt with. Each evaluation step includes independently assessing these aspects of the surrogate to determine where the optimal choice can be achieved.

Sub-component 3.5A. Scientific validity. A wide range of methods has been used to evaluate surrogates including experimental or quasi-experimental intervention, regression and correlation, observation and other approaches. These and other methods have been employed in a range of empirical tests of ecological surrogates such as those of the focal species approach (sensu Lambeck, 1997; Lindenmayer et al., 2014), or of cross-taxon congruence in marine ecosystems (Mellin et al., 2011), aquatic ecosystems (Heino, 2010) and terrestrial ecosystems (Rodrigues and Brooks, 2007; Westgate et al., 2014). Rigorous evaluation of surrogates is important because some surrogates have failed badly. An example from medicine includes the use of arrhythmia as a surrogate for mortality after it was discovered that the drugs encanaide and flecanaide reduced arrhythmia, but actually led to a three-fold increase in mortality (Buyse and Molenberghs, 1998). An example from freshwater ecology includes the failed use of mussels as surrogates for water quality (see the sub-section below on Active Learning) (Millington and Walker, 1983). A controversial example from marine systems is the use of mean trophic level as a surrogate for fishing impacts on food-web integrity (Branch et al., 2010). While it is recognized that the performance of ecological surrogates will never be perfect, it is important to quantify how imperfect they are. For example, Pierson et al. (2015) found that hollow-bearing trees performed reasonably consistently as a surrogate for the occurrence of arboreal marsupials over a large spatial scale, 
474 however there were limits on the predictive ability of the relationship over time. To this end, 475 we suggest clearly identifying spatial and temporal boundaries under which the surrogate 476 relationship is consistent (Ribeiro et al., 2013) (see Trade-off \#3 above).

477 Sub-component 3.5B. Cost-effectiveness. We argue that comparison of benefits and costs 478 among surrogate choices is critical (see Trade-off \#5 above). The true cost of a surrogate 479 approach includes the cost of the previous steps in the Adaptive Surrogacy Framework. In particular, the cost of building a useful conceptual model of the study ecosystem that helps managers to understand the benefits of monitoring can be high if the system is complex.

482 Conversely, if the ecosystem services tied to a particular ecosystem component have a high

483 societal value, such that sensitive decisions will be based on use of the surrogate, the cost 484 may be considered worthwhile. Incorporating costs may therefore encourage managers to consider novel or innovative approaches if a potential surrogate is expensive to employ using traditional techniques but is valuable from an achieving objectives perspective. For example,

487 adopting a surrogate that can be measured using Citizen Science data approaches would 488 leverage effort from volunteers willing to spend their own time and money learning about 489 environmental change and allow a component of the system to be measured that might 490 otherwise have been ignored due to low cost-effectiveness (Jackson et al., 2015). In some 491 cases, having information on multiple components in the conceptual model of the system, 492 including those that are far removed and only indirectly linked to the target, might be 493 unnecessary and a waste of valuable resources. A component that is more 'distant' from the 494 target (see Figure 2) may have a more complex relationship with the target, and may be 495 influenced by many confounding factors. That component would be a less robust, and less 496 accurate surrogate, and thus less cost-effective than a component that is tightly coupled with 497 the target. 
Sub-component 3.5C. Risk-assessment. Formal risk assessment is a way to compare the range of possible outcomes of selecting alternative surrogates by weighing their associated uncertainty with the consequences of making decisions based on the wrong surrogate (Colin et al., 2015). For example, when measuring the effectiveness of a policy that is impacting ecosystem condition (e.g., the ecological integrity of watersheds; Colin et al., 2015), using a surrogate with high communication value and low cost but high uncertainty might initially appear beneficial from a cost-efficiency perspective. From a risk assessment perspective, however, high uncertainty in relation to the outcome, along with high associated costs of public disapproval and decreased watershed condition if the policy fails, are strong disincentives to selection of that surrogate. In such instances, alternative surrogates that have

508 a higher level of certainty and lower ecological risks may be more suitable, despite higher costs. If the risks associated with a particular outcome are particularly high (such as those involving species extinction), then trade-offs sacrificing certainty for lowered costs may not

511 be worth the risk.

\section{6 and 7. Selection and implementation of surrogate}

Once the iterative process of identifying and evaluating potential surrogates is complete, the surrogate that best meets the specific objective can be selected.

\section{Active learning}

Active learning is a central component to the Adaptive Surrogacy Framework. Active

517 learning aims to purposefully design better protocols, to gather information on how the

518 system is changing and/or human interventions are affecting it, and choose to assess the

519 system in a way that improves our understanding of surrogate behaviour. Active learning should focus on key sources of uncertainty in the use of surrogates. For example, it can mean

521 focusing on potential thresholds in relation to a system's response to management actions, or

522 identifying boundaries or exceptions to the expected surrogate-target relationship. Akin to 
523 adaptive management, additional costs may initially apply (Grantham et al., 2009), but could

524 be outweighed by the future benefit of improved accuracy, transferability and/or cost-

525 effectiveness. Active learning of surrogate effectiveness is likely to be most useful where a

526 relationship between surrogates and targets is poorly understood, and uncertainty is high, but

527 key knowledge can be obtained relatively quickly with a focussed study design (e.g., Andean

528 temperate forest avian diversity (Ibarra, 2014), or in cases where unpredictability in the

529 relationship between the surrogate and the target is highly likely (e.g., high climate

530 variability, or risk of habituation/resistant strains in a proxy organism).

531 A good example of active learning in ecological surrogacy comes from work on the

532 Australian Flood Plain Mussel or Freshwater Mussel (Velesunio ambiguous) from the rivers

533 and wetlands of eastern Australia. Early research suggested that the species may be a good

534 indicator of heavy metal pollution in river ecosystems (Walker, 1981). This, in turn, would

535 have provided significant cost savings for monitoring water quality, particularly for human

536 consumption and water-based recreation activities. However, active learning about the

537 mussel's surrogacy value was enhanced by ecophysiological research that revealed that the

538 species' uptake of heavy metals such as zinc, iron and manganese does not reflect ambient 539 concentrations of these elements (Millington and Walker, 1983). This occurred because the

540 mussels avoided metals by significantly curtailing siphoning, movement, and valve opening.

541 Without such active learning, authorities would have deemed water bodies to have limited

542 levels of water pollution when in fact significant public health risks were present.

543 There are numerous other examples of highly effective active learning in the use of

544 ecological surrogates. The continuing evolution and increasing efficacy using lichens as a

545 measure of air pollution and airshed quality is a classic example, particularly as the major

546 drivers of air quality have changed over time (reviewed by Branquinho et al., 2015). 
Advantages of the Adaptive Surrogacy Framework

The Adaptive Surrogacy Framework can be used to guide the deployment of pilot studies to help determine whether an ecological surrogacy approach or a direct approach (sensu Lindenmayer and Likens, 2011) is most effective. Similarly, the sub-components of

552 the evaluation part of the proposed new Adaptive Surrogacy Framework could provide a

553 framework to test the spatial and temporal boundaries within which a given surrogate is robust. Transferability of ecological surrogates in space and time is a key challenge in all disciplines where surrogates are used.

The Adaptive Surrogacy Framework will be particularly useful for understanding how and when to take advantage of emerging opportunities like the advent of new technology (Box 2). It will also be critically important where rapid changes in ecosystems result in past surrogates being superseded and new (more sensitive) ones being needed as environmental conditions degrade or, conversely, improve over time (Pinho et al., 2011). For example, particular species of lichens were originally used as ecological surrogates in monitoring

562 atmospheric pollution, especially concentrations of sulphur dioxide (Hawksworth, 2002).

563 However, there was a transition from the use of individual species of lichens as ecological surrogates to using functional traits of lichens to give broader generality beyond site-specific applications to increase predictive capability in responses across larger areas (Pinho et al., 2011). Indeed, there is considerable potential for greater use of functional diversity approaches in the application of environmental surrogates, particularly as they can provide

568 important additional perspectives or generalisations that are absent when other measures of 569 biodiversity (e.g. species richness) are the sole focus of research, monitoring and management (e.g. Lindenmayer et al., 2015). In cases where a new surrogate is chosen, it is

571 important to calibrate the new surrogate with the old one so the integrity of long-term 
datasets can be maintained (Augusto et al., 2010). Failure to do this can lead to misleading results and precipitate errors in management (Shapiro and Swain, 1983).

574

575

576

577

578

579

580

581

582

583

584

585

586

587

588

589

590

591

592

593

594

\section{BOX 2. The potential of new technologies to improve ecological surrogacy}

Important new frontiers are opening up in the development and application of new kinds of ecological surrogates, as well as advances that allow easier direct measurement of the target of interest in some cases. These new metrics take surrogates beyond the typical domains of species, species richness, and community composition to look at additional forms of biodiversity.

Advancements in genetic techniques are driving new developments in surrogate ecology. Technological advances now allow relatively inexpensive collection of genetic data using increasingly non-invasive approaches (e.g., scat collection, environmental DNA) (BejaPereira et al., 2009). In some cases, particularly using environmental DNA approaches (Ficetola et al., 2008), direct measurement of species presence will become easier than a surrogate approach. Non-invasive genetic methods also allow measurement of demographic features such as population size (Luikart et al., 2010) and population immigration (De Barba et al., 2010). As ecological surrogates, genetic metrics can fill a wide niche as they can be a surrogate for traditional occupancy (Ficetola et al., 2008), population threats such as fragmentation (England et al., 2010), spread of invasive species (Hohenlohe et al., 2011), changes in resilience (Schindler et al., 2010), and population declines (Luikart et al., 1998).

Another technological advancement that will change the cost and usefulness of potential surrogates is the suite of remote sensing technologies (Pettorelli et al., 2014). In particular, high-resolution, low-cost aerial imagery is becoming increasingly available (Watts et al., 2010). Similarly, Light Detection and Ranging (LiDAR) allows accurate measurement of the 3D structure of an ecosystem over much larger spatial scales than is possible using 
601

602

603

604

605

606

607

608

609

610

611

612

613

614

615

616

617

618

619

620 field data collection methods (Listopad et al., 2015). Given the strong relationship many animals have with the structural complexity of a system, the ability to accurately measure this complexity over large spatial scales in a cost-effective manner could lead a new suite of structural metrics that can be used to represent biodiversity.

\section{Conclusion}

Ecological surrogates will continue to be used in all fields and ecosystems because there are insufficient resources and time to work with all entities in all ecosystems at all times. Given this, there is a need to ensure that existing surrogates can be evaluated and improved, or replaced by better ones as they are discovered. Improved surrogate use is complex because of key trade-offs in their identification, development, and application. Our conceptual Adaptive Surrogacy Framework tackles issues associated with these trade-offs and aims to unify surrogate concepts across disciplines and applications. The framework is characterised by inter-linked and iterative identification, application and evaluation steps for continuous testing and improvement, and is suitable for use in all fields where ecological surrogates are employed.

\section{Acknowledgements}

This paper is the outcome of an Australian Research Council funded (FL120100108) international workshop held in October 2014 attended by 18 scientists from 8 different disciplines. Claire Shepherd and Tabitha Boyer assisted with the preparation of this manuscript.

621

\section{References}


623 Andelman, S. J., Fagan, W. F. 2000. Umbrellas and flagships: Efficient conservation

624 surrogates or expensive mistakes? Proc. Natl. Acad. Sci. USA 97, 5954-5959.

625 Ares, A., Aboal, J. R., Carballeira, A., Giordano, S., Adamo, P., Fernández, J. A. 2012. Moss 626 bag biomonitoring: a methodological review. Sci. Total Environ. 432, 143-158.

627 Augusto, S., Máguas, C., Matos, J., Pereira, M. J., Branquinho, C. 2010. Lichens as an 628 integrating tool for monitoring $\mathrm{PAH}$ atmospheric deposition: a comparison with soil, air and 629 vegetation. Environ. Poll. 158, 483-489.

630 Augusto, S., Pereira, M. J., Máguas, C., Branquinho, C. 2013. A step towards the use of 631 biomonitors as estimators of atmospheric PAHs for regulatory purposes. Chemosphere 95, $632 \quad 626-632$.

633 Augusto, S., Pereira, M. J., Máguas, C., Soares, A., Branquinho, C. 2012. Assessing human 634 exposure to PAHs in a petrochemical region based on data from environmental biomonitor. J. Toxic. Environ. Health A 75, 819-830.

636 Barros, C., Pinho, P., Durão, R., Augusto, S., Máguas, C., Pereira, M. J., Branquinho, C.

637 2015. Disentangling natural and anthropogenic sources of atmospheric sulfur in an industrial 638 region using biomonitors. Environ. Sci. Tech. es-2014-03361c.

639 Barton, P., Moir, M. 2015. Invertebrate indicators and ecosystem restoration. In:

640 Lindenmayer, D. B., Pierson, J., Barton, P. (Eds) Surrogates and Indicators in Ecology,

641 Conservation and Environmental Management. CSIRO Publishing, Melbourne.

642 Barton, P., Pierson, J. C., Westgate, M. J., Lane, P. W., Lindenmayer, D. B. 2015. Learning 643 from clinical medicine to improve the use of surrogates in ecology. Oikos 124, 391-398.

644 Beja-Pereira, A., Oliveira, R., Alves, P. C., Schwartz, M. K., Luikart, G. 2009. Advancing 645 ecological understandings through technological transformations in noninvasive genetics.

646 Mol. Ecol. Resources 9, 1279-1301. 
647 Bockstaller, C., Girardin, P. 2003. How to validate environmental indicators. Agric. Sys. 76, $648 \quad 639-653$.

649 Branch, T. A., Watson, R., Fulton, E. A., Jennings, S., McGillard, C. R., Pablico, G. T., 650 Ricard, D., Tracey, S. R. 2010. The trophic fingerprint of marine fisheries. Nature 468, 431651435.

652 Branquinho, C., Matos, P., Pinho, P. 2015. Lichens as ecological indicators for tracking 653 atmospheric changes: future challenges. In: Lindenmayer, D. B., Pierson, J., Barton, P. (Eds)

654 Surrogates and Indicators in Ecology, Conservation and Environmental Management. CSIRO 655 Publishing and CRC Press, Melbourne and London.

656 Breckheimer, I., Haddad, N. M., Morris, W. F., Trainor, A. M., Fields, W. R., Jobe, R. T., 657 Hudgens, B. R., Moody, A., Walters, J. R. 2014. Defining and evaluating the umbrella 658 species concept for conserving and restoring landscape connectivity. Conserv. Biol. 28, 15841593.

660 Buyse, M., Molenberghs, G. 1998. Criteria for the validation of surrogate endpoints in 661 randomized experiments. Biometrics 54, 1014-1029.

662 Buyse, M., Sargent, D. J., Grothey, A., Matheson, A., de Gramont, A. 2010. Biomarkers and 663 surrogate end points - the challenge of statistical validation. Nat. Rev. Clin. Oncol. 7, 309-

664 317.

665 Calhoun, A. J., deMaynadier, P. G. (Eds) 2008. Science and Conservation of Vernal Pools in 666 Northeastern North America. CRC Press, New York.

667 Calhoun, A. J., Jansujwicz, J. S., Bell, K. P., Hunter, M. L. 2014. Improving management of 668 small natural features on private lands by negotiating the science-policy boundary for Maine 669 vernal pools. Proc. Natl. Acad. Sci. USA 111, 11002-11006.

670 Caro, T. 2010. Conservation by Proxy. Indicator, Umbrella, Keystone, Flagship, and Other 671 Surrogate Species. Island Press, Washington D.C. 
672 Colin, N., Poerte, C., Fernandes, D., Barata, C., Padros, F., Carrasson, M., Monroy, M.,

673 Cano-Rocabayera, O., de Sostoa, A., Pina, B., Maceda-Veiga, A. 2015. Ecological relevance

674 of biomarkers in monitoring studies of macro-invertebrates and fish in Mediterranean rivers.

675 Sci. Total Environ.

676 Collen, B., Nicholson, E. 2014. Taking the Measure of Change. Science 346, 166-167.

677 Cury, P. M., Christensen, V. 2005. Quantitative ecosystem indicators for fisheries

678 management. ICES J. Mar. Sci.: J. Conseil 62, 307-310.

679 De Barba, M., Waits, L. P., Garton, E. O., Genovesi, P., Randi, E., Mustoni, A., Groff, C.

680 2010. The power of genetic monitoring for studying demography, ecology and genetics of a

681 reintroduced brown bear population. Mol. Ecol. 19, 3938-3951.

682 Doherty, T. S., Davis, R. A., van Etten, E. J. B., Algar, D., Collier, N., Dickman, C. R., 683 Edwards, G., Masters, P., Palmer, R., Robinson, S. 2015. A continental-scale analysis of feral 684 cat diet in Australia. J. Biogeogr. 42, 964-975.

685 England, P., Luikart, G., Waples, R. 2010. Early detection of population fragmentation using 686 linkage disequilibrium estimation of effective population size. Conserv. Genet. 11, 24256872430.

688 Euliss, N. H., Mushet, D. M. 2011. A multi-year comparison of IPCI scores for prarie pothole 689 wetlands: implications of temporal and spatial variation. Wetlands 31, 713-723.

690 Evans, K., Brown, J. N., Gupta, A. S., Nicol, S. J., Hoyle, S., Matear, R., Arrizabalaga, H. 691 2015. When $1+1$ can be $>2$ : Uncertainties compound when simulating climate, fisheries and 692 marine ecosystems. Deep-Sea Res. II 113, 312-322.

693 Fancy, S. G., Bennetts, R. E. 2011. Institutionalizing an effective long-term monitoring 694 program in the U.S. National Park Service. In: Gitzen, R. A., Millspaugh, J., Cooper, J. A., 695 Licht, D. S. (Eds) Design and Analysis of Long-term Ecological Monitoring Studies.

696 Cambridge University Press, New York. 
697 Ficetola, G. F., Miaud, C., Pompanon, F., Taberlet, P. 2008. Species detection using

698 environmental DNA from water samples. Biol. Lett. 4, 423-425.

699 Friberg, N., Bonada, N., Bradley, D. C., Dunbar, M. J., Edwards, F. K., Grey, J., Hayes, R.

700 B., Hildrew, A., Lamouroux, N., Trimmer, N., Woodward, G. 2011. Biomonitoring of human

701 impacts in freshwater ecosystems: the good, the bad and the ugly. . Adv. Ecol. Res. 44, 1-68.

702 Gardner, T. 2010. Monitoring Forest Biodiversity. Improving Conservation through

703 Ecologically Responsible Management. Earthscan, London.

704 Grantham, H. S., Bode, M., McDonald-Madden, E., Game, E. T., Knight, A. T., Possingham,

705 H. P. 2009. Effective conservation planning requires learning and adaptation. Front. Ecol.

706 Environ. 8, 431-437.

707 Gray, C., Baird, D. J., Baumgartner, S., Jacob, U., Jenkins, G. B., O'Gorman, E. J., Lu, X., 708 Ma, A., Pocock, M. J. O., Schuwirth, N., Thompson, M., Woodward, G. 2014. Forum:

709 Ecological networks: the missing links in biomonitoring science. J. Appl. Ecol. 51, 14447101449.

711 Halpern, B. S., Longo, C., Hardy, D., McLeod, K. L., Samhouri, J. L., Katona, S. K.,

712 Kleisner, K., Lester, S. E., O’Leary, J., Ranelletti, M., Rosenberg, A. A., Scarborough, C.,

713 Selig, E. R., Best, B. D., Brumbaugh, D. R., Chapin, F. S., Crowder, L. B., Daly, K. L.,

714 Doney, S. C., Elfes, C., Fogarty, M. J., Gaines, S. D., Jacobsen, K. I., Karrer, L. B., Leslie, H.

715 M., Neeley, E., Pauly, D., Polasky, S., Ris, B., St Martin, K., Stone, G. S., Sumaila, U. R.,

716 Zeller, D. 2012. An index to assess the health and benefits of the global ocean. Nature 488,

$717 \quad 615-620$.

718 Hansen, M. M., Olivieri, I., Waller, D. M., Nielsen, E. E., GeM Working Group 2012.

719 Monitoring adaptive genetic responses to environmental change. Mol. Ecol. 21, 1311-1329. 
720 Hawksworth, D. L. 2002. Bioindication: calibrated scales and their utility. In: Nimis, P.,

721 Scheidegger, C., Wolseley, P. (Eds) Monitoring with Lichens - Monitoring Lichens. Kluwer

722 Academic Publisher, The Netherlands.

723 Heino, J. 2010. Are indicator groups and cross-taxon congruence useful for predicting

724 biodiversity in aquatic ecosystems? Ecol. Indic. 10, 112-117.

725 Hohenlohe, P. A., Amish, S. J., Catchen, J. M., Allendorf, F. W., Luikart, G. 2011. Next-

726 generation RAD sequencing identifies thousands of SNPs for assessing hybridization

727 between rainbow and westslope cutthroat trout. Mol. Ecol. Resources 11, 117-122.

728 Ibarra, J. T. 2014. Andean Temperate Forest Owls: Detectability, Habitat Relationships and

729 Reliability as Biodiversity Surrogates. University of British Columbia.

730 Jackson, M. M., Gergel, S. E., Martin, K. 2015. Citizen science and field survey observations 731 provide comparable results for mapping Vancouver Island White-tailed Ptarmigan (Lagopus 732 leucura saxatilis) distributions. Biol. Conserv. 181, 162-172.

733 Joint, I., Groom, S. P. 2000. Estimation of phytoplankton production from space: current 734 status and future potential of satellite remote sensing. J. Exper. Mar. Biol. Ecol. 250, 233735255.

736 Kelly, R. P., Erickson, A. L., Mease, L. A., Battista, W., Kittinger, J. N., Fujita, R. 2015.

737 Embracing thresholds for better environmental management. Phil. Trans. R. Soc. B. 370, 73820130276.

739 Kessler, M., Abrahamczyk, S., Bos, M., Buchori, D., Putra, D. D., Gradstein, S. R., Hohn, P.,

740 Kluge, J., Orend, F., Pitopang, R., Saleh, S., Schulze, C. H., Sporn, S. G., Steffan-Dewenter,

741 I., Tjitrosoedirdjo, S. S., Tscharntke, T. 2010. Cost-effectiveness of plant and animal

742 biodiversity indicators in tropical forest and agroforest habitats. J. Appl. Ecol. 48, 330-339.

743 Lambeck, R. J. 1997. Focal species: A multi-species umbrella for nature conservation.

744 Conserv. Biol. 11, 849-856. 
Larson, E. R., Olden, J. D. 2012. Using avatar species to model the potential distribution of emerging invaders. Glob. Ecol. Biogeogr. 21, 1114-1125.

747 Lentile, L. B., Holden, Z. A., Smith, A. M. S., Falkowski, M. J. 2006. Remote sensing

748 techniques to assess active fire characteristics and post-fire effects. Int. J. Wildland Fire 15, $749 \quad 319-345$.

750 Libralato, S., Pranovi, F., Stergiou, K. I., Link, J. 2014. Trophodynamics in marine ecology: 75170 years after Lindeman. Mar. Ecol. Prog. Series 512, 1-7.

752 Lindenmayer, D. B., Blanchard, W., Tennant, P., Barton, P., Ikin, K., Mortelliti, A., Okada, 753 S., Crane, M., Michael, D. 2015. Richness is not all: how changes in avian functional 754 diversity reflect major landscape modification caused by pine plantations. . Divers. Distrib. $755 \quad 21,836-847$.

756 Lindenmayer, D. B., Fischer, J. 2003. Sound science or social hook - a response to Brooker's 757 application of the focal species approach. Landscape and Urban Planning 62, 149-158.

758 Lindenmayer, D. B., Lane, P. W., Westgate, M. J., Crane, M., Michael, D., Okada, S., 759 Barton, P. S. 2014. An Empirical Assessment of the Focal Species Hypothesis. Conserv. Biol. $76028,1594-1603$.

761 Lindenmayer, D. B., Likens, G. E. 2010. Effective Ecological Monitoring. CSIRO Publishing 762 and Earthscan, Melbourne and London.

763 Lindenmayer, D. B., Likens, G. E. 2011. Direct measurement versus surrogate indicator 764 species for evaluating environmental change and biodiversity loss. Ecosystems 14, 47-59.

765 Lindenmayer, D. B., Margules, C. R., Botkin, D. B. 2000. Indicators of biodiversity for 766 ecologically sustainable forest management. Conserv. Biol. 14, 941-950.

767 Lindenmayer, D. B., Piggott, M., Wintle, B. 2013. Counting the books while the library 768 burns: Why conservation monitoring programs need a plan for action. Front. Ecol. Environ. 769 11, 549-555. 
Structural diversity indices based on airborne LiDAR as ecological indicators for managing

772

773

774

775

776

777

778

779

780

781

782

783

784

785

786

787

788

789

790

791

792

793

highly dynamic landscapes. Ecol. Indic. 57, 268-279.

Luikart, G., Allendorf, F., Cornuet, J.-M., Sherwin, W. 1998. Distortion of allele frequency

distributions provides a test for recent population bottlenecks. J. Hered. 89, 238-247.

Luikart, G., Ryman, N., Tallmon, D. A., Schwartz, M. K., Allendorf, F. W. 2010. Estimating census and effective population sizes: Increasing usefulness of genetic methods. Conserv.

Genet. 11, 355-373.

Mandelik, Y., Roll, U., Fleischer, A. 2010. Cost-efficiency of biodiversity indicators for Mediterranean ecosystems and the effects of soci-economic factors. J. Appl. Ecol. 47, 11791188.

McDonald-Madden, E., Baxter, P. W. J., Fuller, R. A., Martin, T. G., Game, E. T., Montambault, J., Possingham, H. P. 2010. Monitoring does not always count. Trends Ecol. Evol. 25, 547-550.

McGeoch, M. A. 1998. The selection, testing and application of terrestrial insects as bioindicators. Biol. Rev. 73, 181-201.

McGill, B. J., Nekola, J. C. 2010. Mechanisms in macroecology: AWOL or purloined letter? Towards a pragmatic view of mechanism. Oikos 119, 591-603.

McManus, E., Jenni, K., Clancy, M., Ghalambor, K., Logan, I., Redman, S., Labiosa, B., Currens, K., Quinn, T., Landis, W., Stiles, K., Burke, J. 2014. The 2014 Puget Sound Pressures Assessment. In. Puget Sound Partnership: Tacoma, Washington Mellin, C., Delean, S., Caley, J., Edgar, G., Meekan, M., Pitcher, R., Przeslawski, R., Williams, A., Bradshaw, C. 2011. Effectiveness of biological surrogates for predicting patterns of marine biodiversity: A global meta-analysis. PLOS One 6, e20141. 
(Phillipi) as a biological indicator for zinc, iron and manganese. Aust. J. Mar. Freshw. Res.

796

797

798

799

800

801

802

803

804

805

806

807

808

809

810

811

812

81

814

815

816 Pinho, P., Theobald, M. R., Dias, T., Tang, Y. S., Cruz, C., Martins-Loução, M. A., Máguas, 817 C., Sutton, M., Branquinho, C. 2012. Critical loads of nitrogen deposition and critical levels

34, 873-892.

Nardo, M., Saisana, M., Saltelli, A., Tarantola, S., Hoffmann, A., Giovannini, E. 2008.

Handbook on Constructing Composite Indices: Methodology and User Guide. OECD

Publishing

Niemeijer, D., de Groot, R. S. 2008. A conceptual framework for selecting environmental indicator sets. Ecol. Indic. 8, 14-25.

Niemi, G. J., Hanowski, J. M., Lima, A. R., Nicholls, T., Weiland, N. 1997. A critical analysis on the use of indicator species in management. J. Wildl. Manage. 61, 1240-1252.

Peck, M. R., Maddock, S. T., Morales, J. N., Oñate, H., Mafla-Endara, P., Peñatfiel, V. A., Torres-Carvajal, O., Pozo-Rivera, W. E., Cueva-Arroyo, X. A., Tolhurst, B. A. 2014. CostEffectiveness of Using Small Vertebrates as Indicators of Disturbance. Conserv. Biol. 28, $1331-1341$.

Pettorelli, N., Laurance, W. F., O'Brien, T. G., Wegmann, M., Nagendra, H., Turner, W. 2014. Satellite remote sensing for applied ecologists: opportunities and challenges. J. Appl. Ecol. 51, 839-848.

Pierson, J. C., Barton, P., Lane, P., Lindenmayer, D. B. 2015. Can habitat surrogates predict the response of target species to landscape change? Biol. Conserv. 184, 1-10.

Pinho, P., Dias, T., Cruz, C., Tang, Y. S., Sutton, M., Martins-Loução, M. A., Máguas, C., Branquinho, C. 2011. Using lichen functional-diversity to assess the effects of atmospheric ammonia in Mediterranean woodlands. J. Appl. Ecol. 48, 1107-1116. 
818 of atmospheric ammonia for semi-natural Mediterranean evergreen woodlands. Biogeosci. 9, $819 \quad 1205-1215$

820 Pinsky, M. L., Palumbi, S. R. 2014. Meta-analysis reveals lower genetic diversity in

821 overfished populations. Mol. Ecol. 23, 29-39.

822 Reilly, S. B., Wake, D. B. 2014. Cryptic diversity and biogeographical patterns within the

823 black salamander (Aneides flavipunctatus) complex. J. Biogeogr. 42, 280-291.

824 Ribeiro, M. C., Pinho, P., Llop, E., Branquinho, C., Soares, A., Pereira, M. J. 2014.

825 Associations between outdoor air quality and birth weight: a geostatistical sequential

826 simulation approach in Coastal Alentejo, Portugal. Stoch. Environ. Res. Risk Assess. 28,

$827 \quad 527-540$.

828 Ribeiro, M. C., Pinho, P., Llop, E., Branquinho, C., Sousa, A. J., Pereira, M. J. 2013.

829 Multivariate geostatistical methods for analysis of biodiversity and environmental factors at 830 multiple spatial scales. Ecol. Indic. 29, 339-347.

831 Rice, J. C. 2003. Environmental health indicators. Ocean Coast. Manage. 46, 235-259.

832 Rice, J. C., Rochet, M. J. 2005. A framework for selecting a suite of indicators for fisheries 833 management. ICES J. Mar. Sci.: J. Conseil 62, 516-527.

834 Rodrigues, A. S., Brooks, T. M. 2007. Shortcuts for biodiversity conservation planning: The 835 effectiveness of surrogates. Ann. Rev. Ecol. Evol. Syst. 38, 713-737.

836 Salo, H. 2015. Mosses as passive and active indicator surrogates for investigations of

837 atmospheric pollution and quality. In: Lindenmayer, D. B., Pierson, J., Barton, P. (Eds)

838 Surrogates and Indicators in Ecology, Conservation and Environmental Management. CSIRO 839 Publishing, Melbourne.

840 Samhouri, J. F., Lester, S. E. S., E.R., Halpern, B. S., Fogarty, M. J., Longo, C., McLeod, K.

841 L. 2012. Sea sick? Setting targets to assess ocean health and ecosystem services. Ecosphere 3, 842 1-18. 
843 Saraux, C., Le Bohec, C., Durant, J. M., Viblanc, V. A., Gauthier-Clerc, M., Beaune, D.,

844 Park, Y.-H., Yoccoz, N. G., Stenseth, N. C., Le Maho, Y. 2011. Reliability of flipper-banded

845 penguins as indicators of climate change. Nature 469, 203-206.

846 Schindler, D. E., Hilborn, R., Chasco, B., Boatright, C. P., Quinn, T. P., Rogers, L. A.,

847 Webster, M. S. 2010. Population diversity and the portfolio effect in an exploited species.

848 Nature 465, 609-612.

849 Seddon, P. J., Leech, T. 2008. Conservation short cut, or long and winding road? A critique

850 of umbrella species criteria. Oryx 42, 240-245.

851 Shapiro, J., Swain, E. B. 1983. Lessons from the silica "decline" in Lake Michigan. Science $852221,457-459$.

853 Sutton, M. A., Wolseley, P. A., Leith, I. D., Van Dijk, N., James, P. W., Theobald, M. R. 854 2009. Estimation of Ammonia critical level for epiphytic lichens based on observations at the 855 farm, landscape and national scales. In: Sutton, M. A., Reis, S., Baker, S. M. H. (Eds)

856 Atmospheric Ammonia- detecting emission changes and environmental impacts. Springer

857 Science Amsterdam.

858 Tallis, H., Levin, P. S., Ruckelshaus, M., Lester, S. E., McLeod, K. L., Fluharty, D. L., 859 Halpern, B. S. 2010. The many faces of ecosystem-based management: Making the process 860 work today in real places. Mar. Pol. 34, 340-348.

861 Travers, M., Shin, Y.-J., Shannon, L., Cury, P. 2006. Simulating and testing the sensitivity of 862 ecosystem-based indicators to fishing in the southern Benguela ecosystem. Can. J. Fish.

863 Aquatic Sci. 63, 943-956.

864 Tulloch, A., Chades, I., Possingham, H. P. 2013. Accounting for Complementarity to

865 Maximize Monitoring Power for Species Management. Conserv. Biol. 27, 988-999.

866 Tulloch, A., Possingham, H. P., Wilson, K. 2011. Wise selection of an indicator for

867 monitoring the success of management actions. Biol. Conserv. 144, 141-154. 
van Straalen, N. M. 1998. Evaluation of bioindicator systems derived from soil arthropod communities. Appl. Soil Ecol. 9, 429-437.

870 Victor, D. G., Kennel, C. F. 2014. Ditch the $2{ }^{\circ} \mathrm{C}$ warming goal. Nature 514, 30-31.

871 Walker, K. F. 1981. Ecology of freshwater mussels in the River Murray. In: Australian

872 Water Resources Council Technical Paper No. 63. Australian Government Publishing

873 Service, Canberra.

874 Watts, A. C., Perry, J. H., Smith, S. E., Burgess, M. A., Wilkinson, B. E., Szantoi, Z., Ifju, P.

875 G., Percival, H. F. 2010. Small unmanned aircraft systems for low-altitude aerial surveys. J.

876 Wildl. Manage. 74, 1614-1619.

877 Westgate, M. J., Barton, P. S., Lane, P. W., Lindenmayer, D. B. 2014. Global meta-analysis

878 reveals low consistency of biodiversity congruence relationships. Nat. Comms. 5, 3899.

879 Wiens, J., Hayward, G. D., Holthausen, R. S., Wisdom, M. J. 2008. Using surrogate species

880 and groups for conservation planning and management. BioScience 58, 241-252.

881 Wintle, B. A., Runge, M. C., Bekessy, S. A. 2010. Allocating monitoring effort in the face of 882 unknown unknowns. Ecol. Lett. 13, 1325-1337. 